Konservasi Hayati, 16 (2): 77-84, Oktober (2020)

https://ejournal.unib.ac.id/index.php/hayati/

p-ISSN: 0216-9487

email:konservasihayati@unib.ac.id

e-ISSN: 2722-1113

\title{
DISTRIBUSI VERTIKAL KOMUNITAS KUMBANG KOTORAN Scarabaeidae DI HABITAT TAMAN NASIONAL GUNUNG SALAK
}

\author{
R. Indarjani ${ }^{1 *}$ dan Mochamad Miko² \\ ${ }^{1,2}$ Universitas Islam As-syafiiyah, Jl. Raya Jatuiwaringin 12 Pondok Gede, Jakarta Timur. \\ *Corresponding author: indarjani61@gmail.com
}

\begin{abstract}
Scarabaeidae dung beettles is a bioindicator through its function as decomposer, Scrabaeidae maintains the balance of environmental conditions that represented by the variation community structures. A study of Scarabaeidae was conducted to observe the variation of community structures related to different heights (900, 1400 dan 2000 masl) in Salak Halimun Mountains National Park (TNGHS), West Java. Pit Fall Dung Trap method was applied in a belt transect paralele with tracking line. In every height, there were 5 traps created with 10 meters distance among each other. In addition, the study also measured main abiotic paramters, such as type of susbtrate, soil acidity, soil temperature that presumed to have strong influence in establishment of the communities. The result showed that there was a variation in community structures related to different heights. In 900 masl, diversity index ( $H^{\prime}$ ) was 0.80 which caterogised as low, in 1400 masl, $H^{\prime}=1,29$ (middle) and $H^{\prime}=0,84$ (low) was found in the 2000 masl. The community structures of Scarabaeidae in TNGHS were made up by genus of Onthophagus dan Copris (Ordo: Coleoptera, Family: Scarabaeidae) that conssits of 4 (four) spesies. They were O. taurus, O. semicupreus, O. babirussoides dan Copris punctulatus. Onthophagus taurus considered as dominant species that filled $60 \%$ or 339 individual of the communities. Meanwhile, Onthopagus babirussoides can be considered as rare species which only $8 \%$ been caught during study.
\end{abstract}

Keywords: beetle dung Scarabaeidae, community structure, vertical distribution, National Park

\begin{abstract}
ABSTRAK
Kumbang kotoran Scarabaeidae merupakan bioindikator kualitas lingkungan melalui perannya sebagai pengurai (decomposer) yang ditunjukan dengan variasi struktur komunitasnya. Studi ini dilakukan untuk mengetahui struktur komunitas vertikal kumbang Scarabaeidae pada ketinggian 900, 1400 dan 2000 mdpl di lingkungan Taman Nasional Gunung Halimun Salak (THNGHS) Jawa Barat. Metode penelitian yang dilakukan adalah Pit Fall Dung Trap dalam suatu belt transect pada lajur pendakian (tracking). Pada setiap ketinggian disiapkan sebanyak 5 (tiga) perangkap mengikuti jalur transect dengan jarak antar perangkap sejauh 10 meter. Pada penelitian ini juga dilakukan pengukuran in situ parameter abiotik utama dianggap mendukung kehidupan hewan tersebut, yakni susbtrat tanah dan $\mathrm{pH}$ tanah. Hasil penelitian ini menunjukkan terjadi perbedaan struktur komunitas pada setiap ketinggian yang ditunjukkan dengan indeks diversitas (H') yakni pada ketinggian 900 mdpl adalah $\mathrm{H}^{\prime}=0.80$ (rendah), $1400 \mathrm{mdpl}$ memiliki $\mathrm{H}^{\prime}=1,29$ (sedang) dan $\mathrm{H}^{\prime}=0,84$ (rendah) dietmukan pada ketinggian 2000 mdpl. Struktur komunitas kumbang di THNGS dibangun oleh 2 (dua) genus kumbang Onthophagus (Ordo: Coleoptera, Family: Scarabaeidae) dan Copris (Ordo: Coleoptera, Family: Scarabaeidae) dari 4 spesies yakni $O$. taurus, O. semicupreus, O. babirussoides dan Copris punctulatus. Species yang mendominasi adalah Onthophagus taurus dengan jumlah individu 339 ekor atau 60\% dari keseluruhan jumlah individu kumbang yang ditangkap pada penelitian ini. Sedangkan Onthopagus babirussoides adalah kategori species jarang (rare species) dengan jumlah koleksi sebanyak 47 individu atau sekitar 8\% dari keseluruhan. Hasil ini memperlihatkan telah terjadi penurunun kualitas lingkungan di TNGHS yang diperlihatkan melalui struktur komunitas Scarabidae dengan keragaman yang relatif rendah.
\end{abstract}

Kata kunci: kumbang kotoran scarabidae, komunitas struktur, distribusi vertikal, THNGS 


\section{PENDAHULUAN}

Sebagai salah satu negara mega diversity dalam sumber hayati, Indonesia memiliki lebih dari 250.000 jenis serangga dimana $40 \%$ serangga berasal dari kelompok Coleoptera atau kumbang. Diperkirakan sekitar 1.000-2.000 spesies kumbang Scarabaeidae hidup di kepulauan IndoAustralia, termasuk Indonesia. Hasil penelitian di Taman Nasional Gunung Halimun, Jawa Barat, berhasil dikoleksi 50 species kumbang kotoran (Noerdjito, 2003), Di Sulawesi ditemukan sekitar 6000 jenis kumbang, dimana 4500 jenis berasal dari hutan dataran rendah Sulawesi Utara (Watt, dkk, 1997 dalam Shahabuddin dkk, 2005). Serangga jenis kumbang mempunyai peran penting dalam menjamin proses aliran energi di alam mengingat perannya sebagai pengurai sampah organik. Hewan Scrabaidae mudah dikenali dari warnanya yang gelap dengan bentuk tubuh cembung, bulat telur atau memanjang, dilengkapi dengan tungkai bertarsi dengan bentuk khas kaki penggali.

Keberadaan kumbang Scarabaeidae sangat berkaitan dengan mamalia, karena kumbang tersebut sangat tergantung pada tinja mamalia sebagai sumber pakan dan substrat untuk melakukan reproduksinya. Itulah sebabnya kumbang jenis Scarabaeidae suka disebut kumbang kotoran (dung beetles). Hewan ini merupakan komponen dekomposer yang sangat penting dalam ekosistem hutan tropis. Kumbang ini dapat mengubur kotoran mamalia 250 kali berat tubuhnya dalam waktu satu malam (Davis, 1993). Perbedaan perilaku makan dan reproduksi kumbang tinja dalam memanfaatkan substrat kotoran menguntungkan lingkungan sekitar karena terjadi perluasan distribusi unsur hara, perbaikan struktur tanah, meningkatkan aerasi bawah tanah (bellow ground), melancarkan laju sirkulasi nutrient yang pada gilirannya berpengaruh pada vegetasi disekitarnya. Untuk itu maka kumbang kotoran Scarabaeidae sering dijadikan sebagai bioindikator untuk melihat tingkat kerusakan hutan tropis dan habitat, karena karena struktur komunitas dan distribusi kumbang kotoran Scarabaeidae sangat dipengaruhi oleh tingkat penutupan vegetasi dan struktur fisik hutan, tipe tanah dan tipe spesies kotoran (Davis dkk,2001 dalam Shahabuddin dkk, 2007 ; Dewi dan Ida, 2012).

Hasil penelitian tentang kumbang Scarabaeidae di Indonesia dilaporkan masih sangat terbatas. Pada tahun 1983, peneliti Hanski menemukan 20 species kumbang Scarabaeidae di Taman National Gunung Mulu, Serawak dan 28 species kumbang ditemukan hidup Taman Nasional Lore Lindu (Shahabuddin dkk, 2005). Kahono dan Setiadi (2006) di T.N Gunung Pangrango juga menemukan 28 spesies. Sedangkan untuk daerah Sumatera Barat penelitian kumbang kotoran Scarabaeidae yang telah dipublikasikan hanya sedikit yaitu penelitian yang dilakukan oleh Mardoni (2011) di Gunung Singgalang dan menemukan 12 spesies kumbang Scarabaeidae serta penelitian Putri dkk (2014) yang menemukan 18 species di Kawasan Cagar Aalam Lembah Harau, Sumatera Barat.

Penelitian ini dilakukan untuk mengetahui kwalitas lingkungan Taman Nasional Salak Gunung Halimun (TNSGH) sebagai destinasi popular dikalangan para pencinta alam dengan melakukan analisa struktur komunitas kumbang kotoran Scarabidae pada berbagai ketinggian dan mengetahui faktor-faktor lingkungan yang berpengaruh pada kehidupan kumbang kotoran. Informasi penelitian diharapkan dapat dijadikan sebagai salah satu sumber rujukan dalam pengelolaan TNSGH yang berkelanjutan.

\section{METODE}

Penelitian dilaksanakan pada bulan November 2016 sampai dengan bulan Januari 2017 di TNGHS Jawa Barat. 


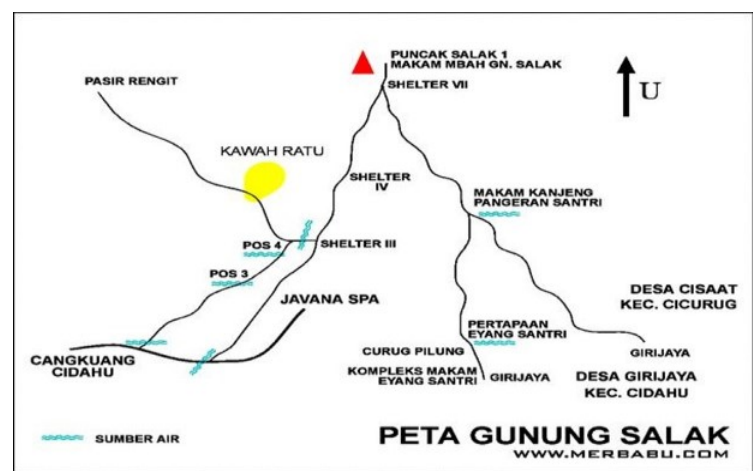

Gambar 1. Lokasi tempat pengambilan sampel, terdiri atas Plot A di ketinggian 900 mdl ; Plot B di ketinggian 1400 mdpl ; Plot C di ketinggian 2000 mdpl

Sampel kumbang diambil dari 3 ketinggian yakni 900 mdpl, 1400 mdpl dan 2000 mdpl. Dengan menggunakan metode kombinasi pit fall dung trap dan belt transect disiapkan lima (5) perangkap yang berjarak masing-masing 10 meter, dengan umpan tinja manusia pada setiap ketinggian. Bentuk perangkap mengikuti rekomendasi Shahabuddin (2007). Belt transect pada penelitian ini merupakan garis transect yang sejajar dengan jalur pendakian dengan mempertimbangkan sifat-sifat vegetasinya untuk menunjukkan bagan pengambilan sampel yang sebenarnya (Soerianegara, 1988). Dengan menerapkan perpaduan metode pit fall dung trap dengan belt transect pada penelitian ini diharapkan pengambilan sampel lebih efektif yakni selain pengambilan data hewannya pada waktu bersamaan dilakukan juga pengambilan data vegetasi dan juga faktor abiotik lainnya secara in situ. Selanjutnya proses pengawetan sampel dan identifikasi dilakukan di Laboratorium Biologi FST-UIA dan di Laboratorium Museum Serangga Taman Mini Indonesia Indah.

Komposisi komunitas kumbang kotoran Scarabaeidae dianalisis melalui indeks biologi yakni keragaman ShannonWiener (H'), kemerataan ( E), Kelimpahan $(\mathrm{Ab})$, Keseragaman serta Dominansi (Shahabuddin, 2007)

\section{HASIL DAN PEMBAHASAN}

\section{A. Komunitas Kumbang Kotoran Scarabaeidae}

Struktur komunitas kumbang Scarabaeidae dibangun oleh 4 spesies yakni Onthophagus taurus, Onthophagus babirussoides, Onthophagus semicupreus, Onthophagus semicupreus, dan Copris puntulatus
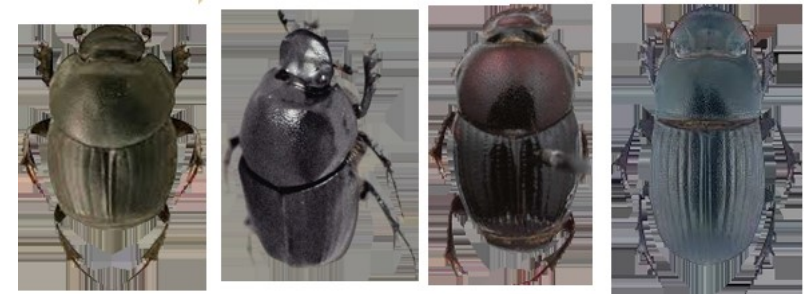

Gambar 2. Jenis kumbang kotoran yang ditemukan di THNGS. Ki-ka: 1.Onthophagus taurus, 2. Onthophagus babirussoides, 3. Onthophagus semicupreus 4. Copris punctulatus

Dari 561 ekor kumbang yang tertangkap dapat dilaporkan bahwa spesies Ontohopagus Taurus mendominasi struktur komunitas kumbang di TNGHS dengan jumlah total yang ditangkap sebanyak 339 ekor atau $60 \%$ dari jumlah kumbah secara keseluruhan. Selanjuutnya Copris punctualis sebanyak 99 ekor atau 18\%, Onthopagus semicupreus sebanyak 76 ekor atau $14 \%$ dan teragir adalah Onthopagus babirussoides sebagai taksa yang paling sedikit jumlahnya (rare taxa) yakni hanya 47 ekor atau $8 \%$.

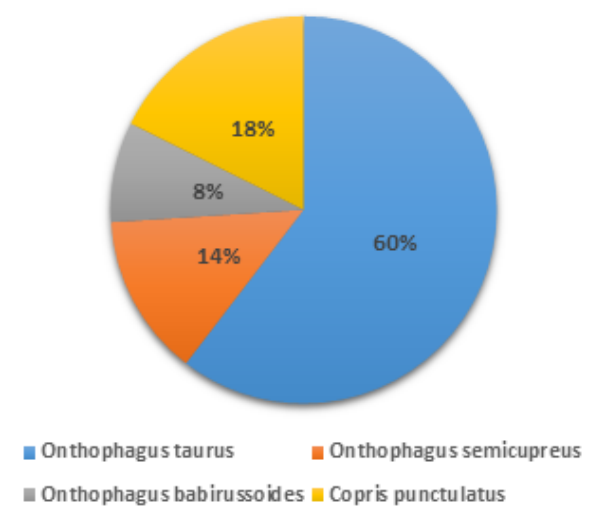

Gambar 3. Diagram memperlihatkan struktur komunitas kumbang kotoran Scarabeideae di TGHNS dimana satu sepcies mendominasinya

Dari data diatas terlihat bahwa genus Onthophagus, khususnya spesies Onthophagus taurus dapat dikategorikan sebagai taxa dominan dari komunitas kumbang kotoran yang hidup di TNGHS. Tampaknya karakteristik habitat TNHGS menunjang kehidupan hewan tersebut secara optimal. Paramitha dan Kasmara (2016) melaporkan suhu optimum keumbang kotoran 
Scarabaiedae pada suhu $25^{\circ} \mathrm{C}$ konsisten dengan temperature lokasi yakni $24-{ }^{\circ} \mathrm{C}-26^{\circ} \mathrm{C}$, serta tututupan tajuk yang relatif rapat, seperti yang disampaikan oleh Kahono dan Setiadi (2007). Habitat preference adalah habitat yang cocok dan dapat ditoleransi suatu species untuk berkembang biak secara optimal. Konsep habitat preference ini bermanfaat untuk praktek budidaya dengan cara memanipulasi kondisi lingkungan hingga cocok untuk kehidupan suatu species (Satyam dan Thiruchitrambalam, 2018). Gambaran struktur komunitas kumbang kotoran di TNGHS sejalan dengan penelitian Kahono dan Setiadi (2007) di gugusan Taman Nasional Gunung Pangrango yang memiliki karakteristik lingkungan yang relatif sama. Dari 28 species yang ditemui 21 species berasal dari genus Onthophagus dan hanya 3 species saja yang berasal dari genus Copris.

\section{B. Distribusi vertiKal kumbang kotoran Scarabaeidae}

Selanjutnya penelitian ini juga mengungkapkan fakta tentang distribusi vertical hewan kumbang kotoran yakni berdasarkan perbedaan ketinggian habitat pegunungan. Parangkap kumbang diletakkan pada 3 ketinggian yang berbeda yakni 900 meter diatas permukaan laut (mdpl), 1400 mdpl serta 2000 mdpl. Temperatur berkisar antara $26-28^{\circ} \mathrm{C}$ dengan rentang kelembaban 97-99\%. Data memperlihatkan bahwa jumlah kumbang yang tertangkap sejalan dengan ketinggian habitat yakni semakin tinggi semakin berkurang jumlahnya.
Tabel 3.1.Distribusi vertikal kumbang kotoran pada setiap ketinggian (mdpl) di THNGS

\begin{tabular}{|c|c|c|c|c|c|c|}
\hline \multirow[t]{2}{*}{$\begin{array}{l}\mathbf{N} \\
\mathbf{0}\end{array}$} & \multirow[t]{2}{*}{ Genus } & \multirow[t]{2}{*}{ Species } & \multicolumn{3}{|c|}{$\begin{array}{l}\text { Jumlah } \\
\text { individu per } \\
\text { ketinggian }\end{array}$} & \multirow[t]{2}{*}{$\begin{array}{l}\text { Jumla } \\
\text { h }\end{array}$} \\
\hline & & & 900 & $\begin{array}{l}08 \\
140 \\
0\end{array}$ & $\begin{array}{l}200 \\
0\end{array}$ & \\
\hline 1 & $\begin{array}{l}\text { Onthophag } \\
\text { us }\end{array}$ & $\begin{array}{l}\text { Onthophag } \\
\text { us taurus }\end{array}$ & $\begin{array}{l}27 \\
2\end{array}$ & 60 & 6 & 339 \\
\hline 2 & $\begin{array}{l}\text { Onthophag } \\
\text { us }\end{array}$ & $\begin{array}{l}\text { Onthophag } \\
\text { us. } \\
\text { semicuoreu } \\
\text { s }\end{array}$ & 32 & 41 & 3 & 78 \\
\hline 3 & $\begin{array}{l}\text { Onthophag } \\
\text { us }\end{array}$ & $\begin{array}{l}\text { Onthophag } \\
\text { us } \\
\text { babirussoid } \\
\text { es }\end{array}$ & 10 & 33 & 4 & 47 \\
\hline 4 & Cipris & C.puntularis & 58 & 39 & 2 & 99 \\
\hline & & Total & $\begin{array}{l}37 \\
3 \\
\end{array}$ & $\begin{array}{l}17 \\
3\end{array}$ & 15 & 561 \\
\hline
\end{tabular}

Tampak ketinggian terendah atau 900 mdpl ditangkap sebanyak 373 ekor kumbang. Selanjutnya pada ketinggian $1400 \mathrm{mdpl}$ terdapat 173 individu. Sedangkan pada pada ketinggian $2000 \mathrm{mdpl}$ hanya ditemukan sebanyak 15 individu jauh lebih sedikit dibandingkan dari ketinggian sebelumnya. Tampak species Onthophagus taurus mendominasi secara jumlah pada setiap ketinggian dengan jumlah terbanya ditemukan pada ketinggian 900 mdpl yakni sebanyak 273 ekor sangat jauh berbeda dengan jumlah yang ditangkap pada keitnggian 2000 mdpl. Terjadinya donimasi suatu taksa pada suatu komunitas akan berpengaruh terhadap indeks biologi yang merupakan representasi dalam menilai tingkat kualitas suatu lingkungan.

Tabel 3.2. Indeks biologi komunitas kumbang kotoran Scarabaeidae di THNGS

\begin{tabular}{|l|l|l|l|l|}
\hline No & Indeks Biologi & \multicolumn{3}{|c|}{ Ketinggian (mdpl) } \\
\cline { 3 - 5 } & & 900 & 1400 & 2000 \\
\hline 1 & $\begin{array}{l}\text { Keanekaragaman } \\
\text { (Diverisitas=H') }\end{array}$ & 0,81 & 1,29 & 0,85 \\
\hline 2 & $\begin{array}{l}\text { Kelimpahan } \\
\text { (Abundance=Ab) }\end{array}$ & 14,92 & 6,92 & 0,6 \\
\hline 3 & $\begin{array}{l}\text { Kemertaan } \\
\text { (Evennes=E) }\end{array}$ & 0,14 & 0,25 & 0,31 \\
\hline
\end{tabular}

Indeks diversitas (H') menunjukkan terjadi variasi yang berbeda dengan trend kelimpahan taxa. Tampak pada ketinggian terendah $900 \mathrm{mdpl}$ indeks keragaman $\left(\mathrm{H}^{\prime}\right)$ bernilai 0,80 atau terendah dibanding dengan ketinggian lainnya dan ketinggian 1400 mdpl 
mempunyai nilai tertinggi yakni 1,2. Kategori indeks keragaman $\left(\mathrm{H}^{\prime}\right)$ di ketiga ketinggian tersebut berkategori rendah hingga sangat rendah (Shahabuddin, 2007). Terjadinya dominansi taxa pada suatu komunitas akan berpengaruh pada penilaian indeks diversitas yang bertumpu pada jumlah proporsional individu suatu taxa terhadap komunitasnya yang sekaligus juga menggambarkan peran dan fungsi ekologisnya dalam komunitas (Odum, 1998). Data indeks kelimpahan terlihat kosisten dengan pernyataan Odum (1998) dimana pada ketinggian $900 \mathrm{mdpl}$ paling tinggi dan cenderung menurun sejalan dengan semakin tingginya habitat tersebut dari permukaan laut. Dalam suatu komunitas yang seimbang atau stabil setiap taksa mempunyai kesempatan yang sama dalam memanfaatkan sumber daya lingkungannya. Hal ini direpresentasikan dengan Indeks Kemerataan (Evenness). Data memperlihatkan bahwa Indeks Kemerataan kumbang Scarabeideae konsisten dengan pernyataan tersebut dimana nilai kemerataan meningkat sejalan dengan ketinggian. Pada ketinggian $900 \mathrm{mdpl}$ mempunyai nilai terendah akibat terjadinya dominasi suatu taksa dan nilai teritnggi didapat pada ketinggian $2000 \mathrm{mdpl}$.

\section{Karakteristik habitat pada setiap ketinggian}

Kawasan Taman Nasional Gunung Halimun Salak (TNGHS) mempunyai luas area 40.000 hektar, merupakan kawasan hutan terluas di Jawa Barat. Topografinya berbukitbukit dengan tipe tanah latosol merah, coklat serta merah kuning. Kawasan tersebut mempunyai iklim tipe A dengan curah hujan cukup tinggi antara 4000-6000 $\mathrm{mm}$, dengan temperatur udara harian rata-rata $18-26^{\circ} \mathrm{C}$ (Kahono dan Arief, 2002). Kawasan ini masih memiliki hutan alam dengan berbagai tipe vegetasi tumbuhan yang berbeda berdasarkan ketinggian yang berbeda pula dan menggambarkan keanekaragaman hayati di kawasan. TNGHS memiliki 1000 spesies tumbuhan diantaranya 850 spesies tumbuhan berbunga. Banyaknya vegetasi dikawasan ini mengakibatkan banyaknya ranting dan kayu lapuk yang berperan sebagai habitat dari larva dan kumbang dewasa. Banyaknya jumlah kumbang dikawasan ini akan berfungsi sebagai perombak bahan organik yang ada disekitarnya (JICA, 2007).

Kumbang kotoran Scarabeidae merupakan serangga kosmopolitan yang bisa ditemukan dihampir semua habitat. Borror, dkk (1989) menegaskan bahwa faktor ketinggian tempat dapat mempengaruhi keberadaan hewan termasuk pada golongan kumbang Coleoptera dimana semakin tinggi tempat dari permukaan laut maka jumlah dan spesies serangga yang ditemukan akan semakin sedikit. Distribusi kumbang kotoran erat kaitannya dengan karakteristik lingkungannya seperti struktur tanah, tingkat keasaman tanah, kelembaban dan temperature.

Merujuk pada hasil penelitian yang dilakukan, tampaknya penyebaran kumbang kotoran Scarabeideae pada ketinggian 900 mdpl dapat dikategorikan sangat luas dengan ditemukan jumlah individu yang sangat melimpah yaitu sebanyak 373 individu (Tabel 3.1). Hal ini disebabkan kondisi lingkungan di plot tersebut relatif mendukung kehidupan jenis-jenis kumbang tertentu. Bentang vegetasi ditempat ini memiliki tutupan kanopi yang rimbun dengan tinggi sekitar antara 20-30 meter yang didominasi oleh pohon Pinus (Pinus mercusii) dan pohon Rasamala ((Altingia exelsa), tingkat dibawahnya adalah jenis tumbuhan tiang dan semak-semak. Struktur tanah pada ketinggian $900 \mathrm{mdpl}$ adalah gembur cenderung keras dan kering dengan warna yang gelap kemerahan dengan $\mathrm{pH}$ tanah sekitar 5,4 dan temperature $26^{\circ} \mathrm{C}$ tampaknya menunjang kehidupan kumbang kotoran Scarabidae. Sebagai serangga permukaan tanah, strategi kumbang kotoran Scarabidae dalam memanfaatkan sumberdaya termasuk kelompok fungsional (guild) tunneler (pembuat terowongan) sehingga didapatkan kelimpahan yang cukup tinggi (Westerwalbelslohl dkk, 2004 dalam Shahabuddin dkk, 2005). Selain itu tempat ini juga merupakan tempat yang popular sebagai camping ground yakni tempat para pendaki bermalam sebelum melanjutkan perjalannya menuju puncak yang meninggalkan ceceran 
sampah. Akibatnya terbentuk makrohabitat yang mengundang hewan mamalia lainnya untuk memanfaatkan sumber daya tersedia. Feses yang dihasilkan dari hewan mamalia tersebut merupakan sumber makanan bagi kumbang kotoran tersebut. Hal ini konsisten dengan telaah Shahabuddin dkk (2005) bahwa potensi terbentuknya makrohabitat akan berdampak positif pada strtuktur komunitas kumbang kotoran. Amirullah (2014) menyatakan bahwa kemerataan vegetasi memiliki kaitan erat dengan distribusi kumbang Coleoptera

Karakteristik habitat pada ketinggian 1400 mdpl berbeda dengan ketinggian sebelumnya. Tutupan kanopi lebih jarang dengan jumlah vegetasi menurun. Tinggi tumbuhan lebih rendah dan kecil-kecil banyak ditemukan tumbuhan epifit dan liana menempel pada pohon khususnya pohon kayu puspa (Schima wallichii). Struktur tanah berbatu, basah, lembut dan sebagian berlumpur dengan warna gelap kehitaman serta memliki temperature $25^{\circ} \mathrm{C}$ dan $\mathrm{pH} 5,5$. Merujuk pada pernyataan Dendang (2009) bahwa keberadan jenis vegetasi pada setiap ketinggian yang berbeda membuat kemerataan spesies Scarabaeidae juga berbeda. Perbedaan ketinggian akan menyebabkan perbedaan pada iklim (seperti suhu, kelembaban dan curah hujan), pola penyebaran vegetasi dan mempengaruhi kemerataan spesies kumbang Scarabaeidae. Indeks Kemerataan (Evenness=E) pada ketinggian $1400 \mathrm{mdpl}$ adalah 0,25 sementara pada ketinggin 900 hanya 0,14 (tabel 3.2). Hal ini konsisten dengan hasil penelitian yang dilakukan di TNGHS.

Karakteristik habitat pada ketinggian 2000 mdpl ditandai dengan semakin jarangnya kerapatan vegetasi. Struktur tanah berpasir, basah dan berbatu dengan warna abu-abu gelap dan agak kehitaman. Temperature pada ketinggian ini lebih dingin yakni $24^{\circ} \mathrm{C}$ dengan $\mathrm{pH}$ tanah sedikit lebih tinggi yakni 5,7. Vegetasi pada ketinggian ini banyak ditemui semak famili Fagaceae. Tumbuhan yang banyak ditemukan di daerah subtropis atau dataran tinggi. Termasuk tumbuhan berbunga (Angiospermae) kategori pohon atau semak (shrubs). Di ketinggian $2000 \mathrm{~m}$ dpl, jumlah kumbang kotoran yang ditemukan paling sedikit yakni hanya 15 ekor (table 3.1). dengan nilai Indeks Kelimpahan (Abundance $=A b$ ) yakni 0,6 namun lokasi ini memiliki Indeks Kemerataan tertinggi yakni 0,3 (table 3.2) jika dibandingkan dengan 2 ketinggian sebelumnya. Menurut Dendang (2009), ukuran keseimbangan antara satu komunitas dengan komunitas lainnya sangat ditentukan oleh nilai indeks kemerataan dan nilai ini dipengaruhi oleh jumlah spesies yang terdapat dalam satu komunitas. Sebagai hewan yang tergolong tunneler (pembuat terowongan) maka struktur tanah mempunyai peran yang penting. Struktur tanah pada ketinggian $2000 \mathrm{mdpl}$ yang berpasir dan berbatu membuat habitat ini kurang disukai oleh kumbang kotoran Scarabeidae. Seperti yang diungkapkan oleh Wiharto dkk (2008) bahwa respon spesies terhadap kondisi kualitas tanah berbeda satu sama lainnya khusus terhadap kisaran kombinasi faktor abiotik tanah dan topgrafi. Pada aliansi yang berbeda akan ditemukan preferensi yang berbeda termasuk adanya tumpang tindih preferensi terhadap faktor biotik, misalnya jenis vegetasi.

\section{PENUTUP}

Penelitian tentang komunitas kumbang kotoran Scarabaeidae di Taman Nasional Gunung Halimun Salak memperlihatkan terjadi distribusi vertikal dari hewan tersebut sejalan dengan ketinggian. Dari perhitungan Indeks Biologi memperlihatkan telah terjadi penurunan kualitas lingkungan taman nasional yang popular diantara para pencinta alam. Terjadinya dominasi species Onthophagus taurus mengindikasikan dengan nilai indeks kelimpahan yang demikian tinggi dibandingkan dengan 3 species lainnya. Profil topografi berpengaruh terhadap kondisi lingkungan abiotik dan biotik. Ketinggian 900 $\mathrm{m}$ dpl tampaknya lebih disukai oleh jenis kumbang kotoran dengan jumlah yang melimpah. Onthophagus taurus mendominasi struktur komunitas kumbang kotoran di TNGHS dan bisa ditemukan disetiap ketinggian, meskipun semakin tinggi semakin 
menurun jumlahnya. Scarabaeidae adalah serangga permukaan tanah dengan gaya hidup sebagai hewan tunneler (pembuat terowongan sebagai tempat menyimpanan makanan) maka karakteristik tanah berpengaruh dalam membentuk struktur komunitasnya. Struktur tanah erat kaitannya dengan jenis vegetasi seperti diperlihatkan pada penelitian ini. Harapannya adalah bahwa informasi yang dihasilkan bisa menjadi rujukan dalam pengelolaan suatu taman nasional yang berkelanjutan dengan memanfaatkan eksistensi bioindikator sehingga gangguan terhadap lingkungan dapat dideteksi sedini mungkin.

\section{DAFTAR PUSTAKA}

Amirullah, Citra Ariani dan Suriana, 2014. Keanekaragaman kumbang Cerambycidae (Coleoptera) Di Kawasan Gunung Mekongga Desa Tinukari Kecamatan Wawo Kabupaten Kolaka Utara Provinsi Sulawesi Tenggara. Bio Wallacea Vol. 1 (1) : Hal. 16-24.

Borror, D.J., C.A. Triplehorn, and N.F. Johnson. 1989. An Introduction to the Study of Insects. 7th Edition. Saunders College Publishing: New York.

Davis, A. J. 1993. The Ecology and Behavior of Dung Beetels in Northern Borneo. University of Leeds, England.

Dendang, B. 2009. Keragaman KuриКири Di Resort Selabintana Taman Nasional Gunung Gede Pangrango, Jawa Barat. Penelitian Hutan dan Konservasi Alam, 6. 25- 36.

Dewi, B.S. dan Ida, P.P. 2012. Ecology's Role Of Dung Beetles As Secondary SeedDisperser In Lampung University.Forestry Department Faculty of Agriculture. University of Lampung.

JICA.2007. Taman Nasional Gunung Halimun-Salak. Email: info@halimun.go.id/mgh(g)telkom.net . Website: www.tnhalimun.go.id. Tanggal Kunjungan 08 Desember 2015.
Kahono, S dan L.K. Setiadi. 2007. Keragamandan Distribusi Vertikal Kumbang Tinja Scarabaeids (Coleoptera: Scarabaeidae) di Hutan Tropis Basah Pegunungan Taman Nasional Gede Pangrango, Jawa Barat, Indonesia. Biodiversitas 7:188122.

Kahono, S. dan A.J. Arief. 2002. Kegiatan penelitian keanekaragaman hayati di Taman Nasiaonal Gunung Halimun (TNGH). Worksop Review BCPJICA. LIPI-JICA-PHPA, Jakarta, 28 Januari 2002.

Mardoni, 2011. Jenis-Jenis Kumbang Tinja (Coleoptera: Scarabaeidae) di Gunung Singgalang. Skripsi. MIPA UNAND. Padang.

Noerdjito, W.A. 2003.Keragaman Kumbang (Coleoptera). Serangga Taman Nasional Gunung Halimun Jawa Bagian Barat. JICA Biodiversity Conservation Project: Bogor.

Odum, E.P. 1998. Dasar-Dasar Ekologi. Jakarta: UGMP

Putri, R, Dahelmi dan Herwina, H. 2014. Jenisjenis Kumbang Tinja (Coleoptera: Scarabaeidae) di Kawasan Cagar Alam Lembah Harau, Sumater Barat. Jurnal Biologi Andalas Vol 3 no 2 E- ISSN 2655-9587

Satyam, Kunal dan Ganesh Thiruchitrambalam, 2018. Biodiversity and Climate Change Adaptation in Tropical Islands. Science Direct

Shahabuddin, Purnama, H., Woro, A.N., Syafrid, M. 2005. Kumbang Tinja (Coleoptera: Scarabaeidae) dan Peran Ekosistemnya. Jurnal Biodiversitas, Vol 6 (2). Jurusan Biologi FMIPA UNS. Surakarta.

Shahabuddin. 2007. Respons Kumbang Koprofagus (Coleoptera: Scarabaeidae) terhadap Perubahan Struktur Vegetasi pada Beberapa Tipe Habitat di Taman Nasional Lore Lindu, Sulawesi Tengah. Jurnal Biodiversitas. Vol 8 (1). Jurusan Biologi FMIPA-UNS. Surakarta. 
Soerianegara 1988. Ekologi Hutan Indonesia. Bandung: Laboratorium Ekologi Hutan Fakultas Kehutanan IPB.

Wiharto, M.C. Kusmana, L.B.Prasetyo dan T. Portomiharjo. 2008. Klasifikasi
Vegetasi Gunung Salak, Bogor, Jawabarat, Jurnal Forum Pascasarjana Vol 31 (1) IPB-Bogor 